
\title{
ОСОБЕННОСТИ ПЕРЕВОДА СОЦИАЛЬНЫХ ДИАЛЕКТОВ НА ПРИМЕРЕ РОМАНА ЧАРЛЬЗА ДИККЕНСА «БОЛЬШИЕ НАДЕЖДЬ»
}

\section{FEATURES OF SOCIAL DIALECT TRANSLATION OF THE EXAMPLE OF CHARLES DICKENS'S NOVEL "GREAT EXPECTATIONS»}

\section{N. Kharchenko S. Usov \\ M. Safonov \\ O. Basherov}

Summary: In modern English there are a large number of dialects. They differ in their lexical, grammatical, syntactic and phonetic characteristics, due to a variety of historical, social and territorial factors. Translation of dialects into other languages, in particular into Russian, can be complicated by insufficient knowledge of all these factors. The purpose of this work is to analyze the influence of causes of a different nature and on the formation of existing dialects and the identification of features and methods of their translation from English into Russian. It is necessary to identify patterns of use of linguistic means depending on the different affiliation of native speakers to certain sectors of society, as well as analyze the use of various expressions, forms, types and types of words that are used in the novel with a focus on social, territorial, professional aspects. Then you can talk about the translation of specific tokens. The material of the study was the text of the artistic work of Charles Dickens "Great Expectations", illustrating the use of dialects in the speech of the characters, as well as its translation into Russian, made by M. Laurier.

Keywords: iterature, translation, Charles Dickens, dialects.
Харченко Николай Леонидович

старший преподаватель, Московский государственный институт физической культуры, спорта и туризма имени Ю. А. Сенкевича

m-rh@mail.ru

Усов Сергей Сергеевич

старший преподаватель, Московский государственный институт физической культуры, спорта и туризма имени Ю. А. Сенкевича ussr-usov@yandex.ru

Сафонов Максим Андреевич старший преподаватель, Московский государственный университет пищевой промышленности

em_kei@mail.ru

Башеров Олег Игоревич старший преподаватель, Российский государственный университет им. А.Н. Косыгина (Москва) olegbasherov@list.ru

Аннотация: В современном английском языке существует большое количество диалектов. Они различаются по своим лексическим, грамматическим, синтаксическим и фонетическим характеристикам, в силу множества исторических, социальных и территориальных факторов. Перевод диалектов на другие языки, в частности на русский, может быть осложнен недостаточными знаниями обо всех этих факторах. Целью данной работы является анализ влияния причин разного характера и на становление существующих диалектов и выявление особенностей и способов их перевода с английского языка на русский. Необходимо выделить закономерности использования языковых средств в зависимости от различной принадлежности носителей языка к тем или иным слоям общества, а также проанализировать употребление различных выражений, форм, типов и видов слов, которые используются в романе с ориентацией на социальные, территориальные, профессиональные аспекты. После чего можно говорить о переводе конкретных лексем. Материалом исследования послужил текст художественного произведения Чарльза Диккенса «Большие надежды», иллюстрирующий употребление диалектов в речи персонажей, а также его перевод на русский язык, выполненный М. Лорие.

Ключевые слова: литература, перевод, Чарльз Диккенс, диалекты. ереводчик сталкивается с большим количеством трудностей, пытаясь найти адекватный эквивалент диалектной лексики. Но перед тем, как перейти к решению вопроса о выборе способа перевода, необходимо проанализировать проблемы перевода такой лексики.

Прежде всего необходимо определить, какой (территориальный или социальный) диалект используется автором. Если художественное произведение написано на местном диалекте, следующим шагом к подходу его перевода будет - понять мотивацию выбора такого языкового варианта. Иногда всё произведение написано на определенном диалекте, в этом случае, используется способ эквивалентного перевода (переводчик должен хорошо владеть данным диалектом). Однако, если диалект является характеристикой героя и его принадлежности к определенной социальной или территориальной группе, необходимо знать способы перевода такой лексики. Диалекты переводимого языка нельзя заменять диалектами языка переводящего, потому что это вызовет совершенно неправильные ассоциации о национальном колорите и не сможет отразить функцио- 
нальную задачу текста оригинала и его прагматическую характеристику. Такая мена теоретически не оправдана и практически не используется.

Территориальные и социальные диалекты тесно связаны между собой. Перевод жаргонизмов и сленговой лексики не представляет таких трудностей, как перевод местных наречий. Это объясняется тем, что характеристика социальных групп не имеет ярко выраженных различий, чего нельзя сказать о территориальных диалектах. Речь людей, принадлежащих к одному профессиональному кругу, но говорящих на разных языках, имеет определенные схожие особенности. Поэтому, например, жаргон английского матроса можно перевести жаргоном русскоговорящих матросов. Использование определенных элементов в переводе должно соответствовать прагматической характеристике самих переведенных элементов [25].

Для достижения адекватности лингвисты используют разные способы перевода [12, с. 46]:

1. создание окказионального (индивидуально-авторского) варианта перевода (М. Лорие в романе Ч. Диккенса «Большие надежды» перевела «супруга вышереченного» как «супруга вышереченного»);

2. калькирование («mass culture» переводится как «массовая культура», «miniskirt» как «мини-юбка») [22];

3. описательный перевод или экспликация («conservationist» - «сторонник защиты окружающей среды», «whistle-stop speech» - «предвыборные выступления кандидата в время агитационной поездки») [23];

4. использование сноски (при непереводимости можно подробно пояснить смысл языковой единицы в переводческой сноске, например, «Out behind them is the line of blue hills; in front is the famous Bakery Hill, and down to the left Golden Point» переводится как «Позади тянется гряда голубых холмов; впереди знаменитый Бейкери Хилл, а внизу налево покинутый прииск Голден Пойнт». К фразе «знаменитый Бейкери Хилл» дается сноска: «Участники Эврикского восстания золотоискателей водрузили мятежное знамя Южного Креста на Бейкери Хилл и приняли революционную присягу») [8];

5. использование приема компенсации («You could tell he was very ashamed of his parents and all, because they said «he don't» and "she don't» and stuff like that.» - «Было видно, что он стесняется своих родителей, потому что они говорили «хочут» и «хочете» и все в таком роде») [24].

Последний прием широко используется в художественной литературе, поэтому следует осветить эту тему в полной мере. Яковлева М.А. в своей диссертации, посвященной теме компенсации в переводе, анализирует труды многих ученых (Я.И. Рецкера, С. Влахова, С. Флорина, Л.С. Бархударова, В.Н. Комиссарова) и формулирует собственное наиболее точное определение термина «компенсация»: «это такой способ перевода, при котором смысл, прагматические значения, а также стилистические нюансы, тождественная передача которых невозможна, а, следовательно, утрачиваемые при переводе, передаются в тексте перевода оттенками другого порядка, причем необязательно в том же самом месте текста, что и в оригинальном варианте» [12, с. 54].

Яковлева М.А. составила собственную парадигму видов этого приема перевода. Она разделяет компенсацию на контактную (если потери компенсируются в том же самом месте ПЯ, что и в тексте ИЯ) и дистантную (потери компенсируются в другом месте ПЯ). Также автор дифференцирует компенсацию на два подвида: горизонтальная (когда в оригинальном тексте единицы одного порядка, утрачиваемые при переводе, воссоздаются единицами того же порядка) и вертикальная (если единицы одного порядка в тексте ИЯ, утрачиваемые при переводе, воссоздаются единицами другого порядка в тексте ПЯ). При этом и горизонтальная и вертикальная компенсации могут быть как контактными, так и дистантными $[12$, с. 58].

Компенсация используется там, где необходимо передать внутрилингвистические значения подлинника (тональность речи, отклонения от языковой нормы, индивидуальные особенности употребления языковых единиц, игру слов и другие). А также, в тех случаях, когда в ПЯ нет прямого эквивалента. Например, при опущении или добавлении звуков: «a-going» вместо нормативного «going», «'ет» вместо «them», «'ourse» вместо «hourse».

Во всех случаях находится определенный эквивалент, возмещающий непереводимый элемент содержания оригинала. Такие трудности иллюстрируют тот факт, что за единицу перевода в данном случае следует брать не конкретное слово, а рассматривать текст в целом, с его языковыми конструкциями и семантикой. Таким образом, восполняется («компенсируется») утраченный смысл, что позволяет выполнить ту функциональную задачу, которую ставил перед собой автор оригинала. При этом, одни элементы текста могут переводиться элементами другого порядка (грамматические значения - лексическими единицами, стилистические особенности синтаксическими конструкциями и тому подобное) [26].

Необходимо кратко сформулировать фабулу произведения, прежде чем указывать на конкретные примеры проявления диалектов в тексте «Больших надежд». Роман повествует об истории одного сироты по имени Пип, который живет со своей авторитарной сестрой и ее мужем Джо Гарджери. Действие происходит в Англии, на сельских болотах Кента. История ведется от лица главного героя как от старого мужчины, рассказывающего 
о своей жизни. Однажды, навещая своих родителей на кладбище, Пип натыкается там на сбежавшего каторжника, и испуганный герой соглашается оказать ему услугу. На следующий день требование принести «жратвы и подпилок» [15] было тайком исполнено Пипом. После чего каторжника снова арестовали и депортировали в Австралию до конца жизни. В это время пожилой богатой леди Мисс Хэвишем требуется товарищ для игр для ее приемной дочери Эстеллы. Девочку она выбрала орудием мести всему мужскому роду за жениха, когдато давно ограбившего ее и разбившего сердце, не явившись на свадьбу. Эстелла сразу заинтересовала Пипа, он находил ее красивой и недоступной. Он еще не раз навещает дом Мисс Хэвишем. Чтобы понравиться холодной Эстелле он готов измениться, стать для нее ровней, для этого ему нужно обучиться манерам. В этот момент в дом Пипа приходит мужчина с именем Джеггерс и заявляет, что некий человек, решивший остаться анонимом, хочет обеспечить Пипа деньгами и отправить его в Лондон, чтобы сделать из него настоящего джентльмена. Главный герой подумал, что это Мисс Хэвишем позаботилась о нем, готовя партию для Эстеллы. Однако, через несколько лет, освоившись в Лондоне, каково было его удивление встретить каторжанина с болот Абеля Мэгвича. Тот рассказывает ему, что это он является его тайным спонсором за проявленное милосердие много лет назад. В этот момент Пип понимает, что Эстелла не уготована ему «самой судьбой». Он узнает, что выходит замуж по расчёту за тирана. Все его надежды летят прахом, но в его душе появляется растущее чувство благодарности Абелю, и он пытается помочь покинуть страну, чтобы остаться непойманным. Старания не обвенчались успехом, Мэгвич был осужден и умер в тюремной камере. И после всех бед, спустя много лет, герой возвращается к тому дому Мисс Хэвишем, где встречает уже овдовевшую Эстеллу. Они берутся за руки и уходят. «Не омрачённые тенью новой разлуки, широкие просторы расстилались перед героями» [15].

В сюжетной линии нашел отражение тот факт, что викторианская Англия (1837 - 1901 гг.) основывалась на классовой системе. Исходя из этого, можно сделать вывод о том, что речь разных социальных слоев существенно различалась. Это прослеживается в произведении ч. Диккенса «Большие надежды». Для доказательства этого утверждения было выбрано несколько героев, а конкретно - Джо Гарджери, Абель Мэгвич, Пип. Они существенным образов отличаются друг от друга своим жизненным опытом, что оставило отпечаток на их произношении и употреблении различных слов и конструкций. Дальше будут приведены примеры речи этих персонажей.

Джо Гарджери - простой, необразованный, сельский кузнец, но добродушный и трудолюбивый. Его можно характеризовать как положительного героя, и в осталь- ных он старался видеть только лучшее. Он происходил из бедной семьи, поэтому у него не было денег для того, чтобы достигнуть высокого социального статуса, в отличии от Пипа. Его речь носит отпечаток его истории, услышав несколько слов, человеку становится ясно, что Джо не имеет какого-либо академического образования и учился всему сам. Поначалу Пип стеснялся своего приемного отца за его ошибки в речи (Джо мог употребить «I were» вместо «l was»), но потом понял, что человека нужно ценить не за его статус, а за доброе сердце.

Диалект Джо во многом отличается от стандартного английского лексикой, реже грамматикой. Пример речи Джо, когда тот приехал навестить Пипа в Лондоне в первый раз: «... 'Your servant, Sir,' said Joe, 'which I hope as you and Pip' - here his eye fell on the Avenger, who was putting some toast on table, and so plainly denoted an intention to make that young gentleman one of the family, that I frowned it down and confused him more - 'I meantersay, you two gentlemen - which I hope as you get your elths in this close spot? For the present may be a werry good inn, according to London opinions,' said Joe, confidentially ...» [16, c. 391].

Джо очутился в незнакомом месте, и по его речи понятно, что он чувствовал некую неловкость. Он давно не видел Пипа и не знал как на него реагировать, поэтому даже обратился к своему приемному сыну «Sir». А целое выражение «Your servant, Sir» создает ощутимую пропасть между ними. Очевидно, что Джо стесняется своей невежественности перед Пипом и его другом, поэтому ставит их выше себя.

Еще одним лексическим отклонением, которое Джо часто употребляет, является «mentersay» вместо «meant to say». Это выражение является неотъемлемой частью героя, из-за повсеместного его употребления.

На фонетическом уровне можно заметить употребление лов «elth» вместо «health» и «werry» вместо «very».

В следующем отрывке Джо использует еще одну лексическую замену: «...Pip,' returned Joe, cutting me short as if he were hurt, 'which I meantersay that were not a question requiring a answer betwixt yourself and me, and which you know the answer to be full well No. You know it to be No, Pip, and wherefore should I say it?' ...» [16, c. 178].

Здесь, помимо «meantersay», можно заметить употребление слова «betwixt» архаичной формы предлога «between». В отличии от «meantersay», «betwixt» используют в своей речи и другие герои (кроме говорящих на литературном английском - Пип, Джеггерс, Эстелла).

Следует рассмотреть еще один пример речи Джо Гарджери: «... My father, Pip, he were given to drink, and when he were overtook with drink, he hammered away 
at my mother, most onmerciful. It were a'most the only hammering he did, indeed, 'xcepting at myself. And he hammered at me with a wigour only to be equalled by the wigour with which he didn't hammer at his anwil. - You're a-listening and understanding, Pip?'

'Yes, Joe.'

"Consequence, my mother and me we ran away from my father, several times; and then my mother she'd go out to work, and she'd say, 'Joe,'she'd say,'now, please God, you shall have some schooling, child,' and she'd put me to school. But my father were that good in his hart that he couldn't abear to be without us. So, he'd come with a most tremenjous crowd and make such a row at the doors of the houses where we were, that they used to be obligated to have no more to do with us and to give us up to him. And then he took us home and hammered us. Which, you see, Pip,' said Joe, pausing in his meditative raking of the fire, and looking at me, 'were a drawback on my learning.' ...» [Там же, с. 79].

Разберем особенности речи героя. В данном отрывке можно заметить повторение одной и той же морфологической ошибки: Джо путает употребление слов «was» и «were». Еще две неточности в произношении слов: «unmerciful», которое употреблено как «omerciful», «tremenjous» вместо нормативного «tremendous» и «bear» заменено словом «abear», вместо «listening» использована устаревшая форма «а-listening». Редуцирование звуков отражается в словах: «a'most» вместо «almost» и «'xcepting» вместо «ехсерting». Герой допускает ошибки на морфологическом уровне в выборе части речи, употребив существительное "consequence», а не наречие «consequently». Джо заменяет звук [v] на звук [w] в словах: «vigour» на «Wigour» и «anvil» на «anwil» (другие примеры: «convict»/«conwict» $[16$, c. 21], «velvet»/«welwet» [Там же, c. 122], «divisions»/«diwisions» [Там же, с. 397]). Иногда можно заметить и обратную замену (звук [w] на [v]).

В последнем рассмотренном отрывке было замечено большое число отхождений от нормативного английского языка. Герой сам объясняет свою невежественность недостаточностью знаний и отсутствием академического образования. Однако мена звуков [w] и [v] является характерной чертой Кентского диалекта (откуда и происходит герой). Именно такие диалектические маркеры отражают принадлежность героя к конкретному социальному классу людей. По его речи можно судить о месте, в котором он рос, а также, о его образовании, а вернее - о его отсутствии.

Рассмотрим речь другого героя - Абеля Магвича. В романе он противопоставляется Пипу, являясь его антиподом на протяжение большей части книги. Впервые перед читателем Абель предстает в образе сбежавшего заключенного, озлобленного, неприятного и видавшего виды. Его грубый диалект контрастирует с литературным произношением английского у Пипа. Диалект Абеля Магвича характеризуется огромным количеством опущений, выраженных на письме апострофами: «...'You young dog,' said the man, licking his lips, 'what fat cheeks you ha' got.'

I believe they were fat, though I was at that time undersized for my years, and not strong.

'Darn me if I couldn't eat em,'said the man, with a threatening shake of his head, 'and if I han't half a mind to't!' ...» [16, c. 5];

«... 'Ha!' he muttered then, considering. 'Who d'ye live with - supposin' you're kindly let to live, which I han't made up my mind about?' ... 'Now lookee here,' he said, 'the question being whether you're to be let to live. You know what a file is?'”es, sir.'And you know what wittles is?' 'Yes, sir.'... 'You get me a file.' He tilted me again. 'And you get me wittles.' He tilted me again. 'You bring 'em both to me.' He tilted me again. 'Or l'll have your heart and your liver out.' He tilted me again. ...» [Там же, с. 6].

В этих отрывках повсеместно встречается отклонение от нормы на фонетическом уровне - редуцирование или «проглатывание» звуков: «ha'» вместо «have», «'em» вместо «them», «han't» вместо «had not»/«has not», «to't» вместо «to it», «d'ye» вместо «would you», «supposin'» вместо «supposing». Речь героя похожа на аббревиацию, а его произношение сильно отходит от норм грамматики английского.

Почти вся 42 глава написана от лица Магвича, для читателя она особенно интересна, потому как именно в ней герой раскрывается в наиболее полной мере. Эта глава привлекает к себе внимание не только обывателя, она также интересна и с лингвистической точки зрения, потому что в ней отражен индивидуальный голос Абеля с его диалектическими особенностями.

"... "And when it comes to character, warn't it Compeyson as had been to the school, and warn't it his schoolfellows as was in this position and in that, and warn't it him as had been know'd by witnesses in such clubs and societies, and nowt to his disadvantage? And warn't it me as had been tried afore, and as had been know'd up hill and down dale in Bridewells and Lock-Ups? And when it come to speech-making, warn't it Compeyson as could speak to 'em wi' his face dropping every now and then into his white pocket-handkercher - ah! and wi' verses in his speech, too - and warn't it me as could only say, 'Gentlemen, this man at my side is a most precious rascal'? And when the verdict come, warn't it Compeyson as was recommended to mercy on account of good character and bad company, and giving up all the information he could agen me, and warn't it me as got never a word but Guilty? ...» [16, c. 622]. 
В этом отрывке речи героя неоднократно проявляется «warn't» вместо нормативного «wasn't» и «weren't» (лингвисты относят такое отклонение от стандарта к разным уровням). Герой вовсе не разделяет их по лицам, используя одно сокращение во всех случаях. Этот факт характеризует стремление героя всё упростить, в отличии, например Джо Гарджери, который допускает ошибки в употреблении этого глагола из-за собственного невежества. Можно сделать много выводов о личности Абеля по его речи. Грубый акцент с опущениями и сокращениями характеризуется его тяжелой судьбой быть нечестно осужденным. Его героя можно назвать комментарием самого Диккенса к гнилой и коррумпированной системе правосудия.

В лексике героя часто встречается «know'd». Это архаичная форма глагола «know» в простом прошедшем времени. Такое употребление характерно для Суррей (Surrey) и Дорсет (Dorset) - южных диалектов (где и находилась тюрьма, в которой Абель провел годы заключения). Нормативное «роcket-handkerchief» заменено диалектным вариантом «роcket-handkercher». Также часто встречается употребление «аs» вместо «that».

В последнем диалоге с Пипом мало что изменилось в речи Абеля с лингвистической точки зрения: «...»Dear boy,» he said, as I sat down by his bed: «l thought you was late. But I knowed you couldn't be that.» ... «Thank'ee dear boy, thank'ee. God bless you! You've never deserted me, dear boy.»...» [Там же, с. 820].

В этом отрывке встречаются те же грамматические ошибки, которые были проанализированы ранее. Что касается лексики, тут можно заметить новое слово «thank'eе» аналогично другим примерам заменяющее «thank you». Речь героя стала не такой грубой (на всех языковых уровнях) как в начале романа, однако, даже употребляя новые конструкции герой адаптирует их «под себя». Это доказывает тот факт, что жизненный опыт, пройденный путь и условия, при которых формировались и закладывались основы характера - всё перечисленное определенным образом отражается в человеческой речи.

Обратимся к другому персонажу - Пипу. По логике, Пип, как и предыдущие рассмотренные герои, должен говорить на диалекте, однако в своей речи он использует стандартный английский на протяжение всего романа (за что Диккенс подвергся критике). С помощью диалектной лексики автор хотел разграничить принадлежность героев к разным социальным слоям. Пип, ставший в итоге настоящим джентльменом, изначально был выбран Диккенсом в качестве примера, иллюстрирующего личностный рост, поэтому его речь служила образцом нормированного употребления английского языка.

Итак, подводя итоги, можно сказать, что в романе диалекты являются не просто способом детализации персонажей, диалекты - маркеры, относящие каждого героя к конкретной социальной группе людей. Диалектная речь разграничивает разные слои общества. В произведении Ч. Диккенса она связана с основными темами романа: с социальной мобильностью, ожиданиями в контрасте с реальностью, знатностью и аристократией, и несправедливостью Викторианского общества. Исходя из анализа речи героев, можно убедиться в том, что на вариативность языка влияют как социальные, так и территориальные факторы. Образование человека или его отсутствие является одним из ключевых моментов, сказывающихся на употреблении определенных конструкций, лексем, грамматических форм и семантических единиц. Оно, как правило, характеризует степень отклонения речи человека от общепринятого языкового стандарта на разных языковых уровнях. На базе анализа приведенных примеров, было обнаружено, что на фонетическом уровне прослеживается наибольшее количество отклонений от нормы, далее по частоте употребления идут лексико-фразеологический и морфологический уровни. На уровне синтаксиса несоответствий выявлено не было.

В результате проведенного исследования, были сделаны следующие выводы:

1. на формирование современного стандартного английского языка и диалектов оказывают влияние множество факторов: происхождение этносов, заимствования из других языков в результате территориальной экспансии, социальная дифференциация общества в процессе исторического развития общества, тенденции в развитии языка и культуры;

2. развитие культуры способствовало выделению из языка территориальных и социальных диалектов, которые существуют в современном мире наряду с нормативным английским;

3. диалекты обладают внутрилингвистическими значениями, поэтому для их перевода подходят аналитические способы передачи смысла текста: 1) описательный, 2) переводческая сноска, 3) калькирование, 4) прием компенсации;

4. диалекты - маркеры, определяющие принадлежность человека к определенной социальной страте или группе, его локализацию и уровень образования (выявлено на основе сравнения речи героев романа Ч. Диккенса «Большие надежды» со стандартом английского языка);

5. при сопоставительном анализе речи героев, было обнаружено, что наибольшее количество диалектных отклонений от нормированного английского встречается на фонетическом уровне языка, а наименьшее - на синтаксическом;

6. за единицу перевода при переводе диалектов следует брать не конкретное слово, а рассматри- 
вать текст в целом, с его языковыми конструкциями и семантикой. Таким образом, восполняется («компенсируется») утраченный смысл текста, что позволяет передать то функциональное значение, которое хотел передать автор оригинала;

7. практика показала, что существуют закономерности перевода диалектных отклонений определенного уровня английского языка определенными единицами русского языка. Диалектные конструкции фонетического, морфологического и лексикофразеологического уровня переводятся в основном лексикой русского языка, редко единицами морфологического и синтаксического уровня. Было выявлено, что при переводе, почти никогда не используются средства фонетического уровня русского языка.

\section{ЛИТЕРАТУРА}

1. Аракин В.Д. История английского языка. - М.: ФИЗМАТЛИТ, 2003.

2. Бархударов Л.С. Язык и перевод: вопросы общей и частной теории перевода./ /Л.С. Бархударов - М.: Международные отношения. 1975. - 237стр.

3. Иванова И.П., Чахоян Л.П. История английского языка. - М, 1971.

4. Ильиш Б.А. История английского языка. - М.: Высш. школа, 1968. - 420 с

5. Казакова, Т.А. Художественный перевод: в поисках истины [Текст]// Т.А. Казакова; - СПб., 2006. - 224с

6. Лихачев Д. Черты первобытного примитивизма воровской речи. Язык и мышление./ /А.Д. Лихачев - М.-Л., 1935

7. Маковский М.М. Английские социальные диалекты (онтология структура, этимология): Учеб. Пособие. - М.: Высш. Школа, 1982. - с. 135

8. Писковец Т.А. Австралийские микротопонимы в оригинале и переводе (на материале произведений австралийских писателей): (татья. - М.: Издательство Грамота, 2014.

9. Расторгуева Т.А. История английского языка: Учебник. - М.: 000 Издательство Астрель: Издательство АСТ, 2001. - 352 С. ИЛ.

10. Субич В.Г. Диалекты британского варианта английского языка. - М, 2002.

11. Швейцер А.Д. Современная социолингвистика. Теория, проблемы, методы.// А.Д. Швейцер; - М., 1976.

12. Яковлева М.А. Компенсация при передаче стилистически сниженных высказываний на разных уровнях текста: Диссертация. - М.: МГлУ, 2008,130 c.

13. Coleman St. D. Dialects, Jargon and slang. - Douglas: Folklore acad., $196 \mathrm{p}$.

14. Sweet H. A New English Grammar. Logical and Historical. Part II. Syntax. -Oxford.: Clarendon press, 1958, 127 p.

15. Ч. Диккенс. Большие надежды: перевод М.Ф. Лорие. - М.: Гослитиздат, 1952. - 480 с.

16. Ch. Dickens. Great Expectations. [Электронная версия] Planet PDF

17. Тимофеев, Л., Тураев, С. Словарь литературоведческих терминов.// Под ред. Л. Тимофеева, С. Тураева. - М.: Просвещение, 1974

18. Green, J. Dictionary of jargon . //- London, 1987. - $301 \mathrm{c}$.

19. The Oxford dictionariy of modern slang. - New York; Oxford:Oxford university press, 1992.- $299 \mathrm{c}$.

20. Галь Н. Слово живое и мёртвое [Электронный ресурс] / Режим доступа: http://linguistis.narod.ru/downloads6.html.\#nora

21. Гальперин И.Р. Стилистика английского языка [Электронный ресурс]/ Режим доступа: www.e-lingvo.net/files/unfo/30/2/65, свободный

22. Комисаров В.Н. Теория перевода (лингвистические аспекты). [Электронный ресурс] / Режим доступа: http://www.classes.ru/grammar/Teoriya_perevoda_ Lingvicticheskiye_aspekty/extfile/help2/html/unnamed_28.html

23. Комисаров В.Н. Теория перевода лингвистический аспект. [Электронный ресурс] / Режим доступа: http://www.classes.ru/grammar/Teoriya_perevoda_ Lingvicticheskiye_aspekty/extfile/help2/html/unnamed_34.html

24. Комисаров В.Н. Теория перевода лингвистический аспект. [Электронный ресурс] / Режим доступа: http://www.classes.ru/grammar/Teoriya_perevoda_ Lingvicticheskiye_aspekty/extfile/help2/html/unnamed_35.html

25. Комисаров В.Н. Теория перевода лингвистический аспект. [Электронный ресурс] / Режим доступа: http://www.classes.ru/grammar/Teoriya_perevoda_ Lingvicticheskiye_aspekty/extfile/help2/html/unnamed_52.html

26. Проблема перевода диалектизмов. [Электронный ресурс] / Режим доступа: http://lib.rosdiplom.ru/library/prosmotr.aspx?id=496666.

27. Русские слова в английском языке [Электронный ресурс] / Режим доступа: http://www.study.ru/support/lib/40.html.

28. Словарь английского сленга [Электронный ресурс]/ Режим доступа: www.langinfo.ru/ slang.

29. Статистика наиболее привлекательных диалектов Британии [Электронный ресурс] / Режим доступа: http://www.mirror.co.uk/news/uk-news/most-andleast-attractive-accents-6270249.

30. Художественное пространство словесного произведения [Электронный ресурс] / Режим доступа: http://ksana-k.narod.ru/Book/poet/30.html

31. Чарльз Диккенс «Большие надежды» [Электронный ресурс] / Режим доступа: http://www.lib.ru/INPROZ/DIKKENS/d23.txt

32. Швейцер А.Д. Теория перевода. М.: Наука 1988 [Электронный ресурс]/ Режим доступа: www.auditorium.ru/books/2406

33. English accents. [Электронный ресурс] / Режим доступа: http://www.bl.uk/learning/langlit/sounds/regional-voices/phonological-variation/

34. Joe Gargery in GE. [Электронный ресурс] / Режим доступа: http://www.shmoop.com/great-expectations/joe-gargery.html

(c Харченко Николай Леонидович (m-rh@mail.ru), Усов Сергей Сергеевич (ussr-usov@yandex.ru),

Сафонов Максим Андреевич (em_kei@mail.ru), Башеров Олег Игоревич (olegbasherov@list.ru). 